\title{
Paul Münch
}

\section{Grundwerte der frühneuzeitlichen Ständegesellschaft? Aufriß einer vernachlässigten Thematik}

Nach der Existenz von ,Grundwerten“ in der ständischen Gesellschaft zu fragen, muß auf den ersten Blick als ein anachronistisches Unterfangen erscheinen. Die begriffliche Nähe der ,Grundwerte' zu den Grund-, Menschen- und Freiheitsrecbten ${ }^{1}$, die erst seit dem späten 18. Jahrhundert das Orientierungsfundament der heraufziehenden bürgerlichen Gesellschaft bilden ${ }^{2}$, legt nahe, Grundwerte ebenfalls erst für die bürgerlich-konstitutionelle Epoche anzunehmen. Setzt nicht die vielfach geschichtete, aus rechtlich und sozial autonomen, societates ' gebildete Struktur des alten Gemeinwesens eine gleichermaßen fraktionierte Werteordnung voraus? Und kann nicht erst die durch die absolutistischen Nivellierungstendenzen vorbereitete eine, bürgerliche Gesellschaft als Basis einer allgemein verbindlichen Werteordnung fungieren?

In der Tat beginnt die einklagbare Geltung eines kohärenten Kanons von Grundund Freiheitsrechten erst mit dem konstitutionellen Zeitalter. Und doch scheint es nicht unnütz zu sein, die Frage nach den Grundwerten auch für die vormoderne Gesellschaft zu stellen. Dabei geht es nicht um die in und über die Ständegesellschaft partiell hinein- und hinausreichende Vorgeschichte der modernen bürgerlichen Grundrechte $^{3}$, sondern um die Frage, ob es nicht auch in der ständischen Gesellschaft einen die sozialen Schichten und Räume ganz oder partiell überwölbenden Vorrat an Grundanschauungen gegeben hat, einen Kanon von Orientierungen, der den Bau der Ständegesellschaft zusammengehalten und gleichsam fundamentiert hat.

Dieser Beitrag versucht nach einem Blick auf die Forschungslage (I) die in der gegenwärtigen historischen Literatur gelāufigsten, an bestimmte Werte gekoppelten Makro-Erklärungsmodelle des frühneuzeitlichen historischen Wandels zu kritisieren (II),

' Karl August Bettermann, Franz L. Neumann, Hans Carl Nipperdey, Ulrich Scheuner (Hgg.), Die Grundrechte. Handbuch der Theorie und Praxis der Grundrechte (5 Bde., Berlin 1961).

${ }^{2}$ Gerhard Oestreich, Geschichte der Menschenrechte und Grundfreiheiten im Umriß (Historische Forschungen 1, Berlin 1968) mit ausführlicher Bibliographie; Günter Birtsch (Hg.), Grund- und Freiheitsrechte im Wandel von Gesellschaft und Geschichte. Beiträge zur Geschichte der Grundund Freiheitsrechte vom Ausgang des Mittelalters bis zur Revolution von 1848 (Veröffentlichungen zur Geschichte der Grund- und Freiheitsrechte 1, Göttingen 1981).

${ }^{3}$ Etwa die Geschichte der Freiheit oder Gleichheit. Vgl. hierzu Jürgen Scblumbobm, Freiheit. Die Anfänge der bürgerlichen Emanzipationsbewegung in Deutschland im Spiegel ihres Leitworts (ca. 1760-ca. 1800). (Düsseldorf 1975); Otto Dann, Gleichheit und Gleichberechtigung. Das Gleichheitspostulat in der alteuropäischen Tradition in Deutschland bis zum ausgehenden 19. Jahrhundert (Berlin 1980); vgl. auch die Beiträge des in Anm. 2 genannten Sammelbandes. 
um abschließend den Versuch zu unternehmen, einige Grundwerte der frühneuzeitlichen Ständegesellschaft wenigstens umrißhaft zu beschreiben (III) ${ }^{4}$.

Das Terrain der Werteforschung gleicht einem sich unendlich dehnenden, noch weithin dunklen Labyrinth. Auf ihm tummeln sich, wie es ein DFG-Schwerpunkt ,Interdisziplinäre Wertforschung ${ }^{65}$ ausweist, über zehn wissenschaftliche Disziplinen. Der hierbei angesprochene „Objektbereich" ist umfassend, er beansprucht „die Gesamtheit der Ordnungsstrukturen, worin die individuelle und soziale menschliche Existenz in Gesellschaft und Geschichte ihre jeweilige empirische Gestalt gewinnt oder gewinnen soll. Solche Strukturgefüge oder Figurationen stellen sich als Sinnzusammenhänge und Haltungen der individuellen und sozialen Existenz dar, die für jede gesellschaftliche Ordnung und für individuelles Verhalten konstitutiv sind und in gesellschaftlichen Symbolwelten, z. B. der Religion, der Literatur, des Rechts und der Kunst mehr oder weniger vollständigen Ausdruck finden. " ${ }^{6}$ Der methodische Zugriff der Werteforschung besitzt ein breites, konkurrierendes Spektrum, die Begrifflichkeit erscheint bis heute nicht eindeutig. Rüdiger Lautmann hat in einer Analyse des Gebrauchs der Begriffe ,Wert' und ,Norm' nicht weniger als 178 differierende Wertdefinitionen und immer noch halb so viel unterschiedliche Bedeutungen des Normbegriffs ausmachen können ${ }^{7}$, ein für die wissenschaftliche Forschungsarbeit wenig ermutigender Befund.

Es verwundert deswegen kaum, daß die historische Erforschung der in der Ständegesellschaft wirksamen Wertewelten bis heute erst ansatzweise in Angriff genommen ist. Die defiziente Forschungssituation resultiert allerdings nicht nur aus der Unübersichtlichkeit des Gegenstandes, dem Mangel einschlägiger methodischer Strategien oder den begrifflichen Aporien, die Zurückhaltung der historischen Forschung hat noch andere Ursachen. Zumal die Reserve der deutschen Geschichtswissenschaft gegenüber der Werteforschung dürfte, worauf Wolfgang Hardtwig aufmerksam gemacht hat, „in der negativen Konnotation zu suchen sein, der dem Wertbegriff aus der Wertbzw. Relativismusdebatte um den Historismus in den 20er Jahren anhaftet ${ }^{\text {c8 }}$. Erst kürzlich erschien es beispielsweise Karl Erich Born anläßlich der Diskussion der ,preußischen Tugenden“ angebracht, vor dem seiner Ansicht nach damit verbundenen

${ }^{4}$ Das kann angesichts des zur Verfügung stehenden Raumes nur in einigen Aspekten erfolgen. Die Thematik, die hier angerissen ist, bedarf, bevor eine Synthese möglich wird, noch vieler Einzelstudien.

s 5. Fassung (Mai 82), maschinenschriftlich.

${ }^{6}$ Ebenda 1.

7 Rüdiger Lautmann, Wert und Norm. Begriffsanalysen für die Soziologie (Opladen 1971) 98. Ich verzichte auf eine Bibliographie weiterer soziologischer Literatur, mit der sich viele Seiten füllen ließen. Die meisten soziologischen Studien sind gegenwartsorientiert. Vgl. zum Beispiel Helmut Klages, Wertorientierungen im Wandel. Rückblick, Gegenwartsanalyse, Prognosen (Frankfurt a.M., New York ${ }^{2} 1985$ ).

${ }^{8}$ Zur Wertforschung der Geschichtswissenschaft. In: Antrag DFG-SP: Interdisziplinäre Wertforschung (wie Anm. 5) 67. 
Abgleiten in den ,Bereich der Metaphysik‘ zu warnen?. Hinzu kommt, daß die perverse Funktionalisierung bürgerlicher Werte, die Barbarisierung des bürgerlichen Tugendkanons während des 3. Reichs wegen ihrer Belastung für die eigene nationale Identität einen unbefangenen Zugriff der deutschen Geschichtsforschung begreiflicherweise bislang eher verhindert hat ${ }^{10}$.

Jenseits der in den westlichen Demokratien aus Legitimationsgründen traditionell mit Nachdruck betriebenen juristischen Beschäftigungen mit den Grund- und Freiheitsrechten, die gewöhnlich auch historische Bezüge einschließt ${ }^{11}$, scheint sich die historische Forschung auf die Analyse sozialer und allgemein politischer Wertewelten bisher systematisch noch wenig eingelassen zu haben. Klammert man die philosophischen und theologischen Arbeiten zur Geschichte der Ethik aus ${ }^{12}$, läßt man die problematischen germanistischen Studien zum ritterlichen Tugendsystem beiseite ${ }^{13}$, dann bleiben relativ wenige Schwerpunkte übrig, denen sich die historisch orientierte Werteforschung inzwischen zugewandt hat. Erste Ergebnisse hat der schichtenspezifische Zugriff gezeitigt. Über die Wertorientierungen der frühneuzeitlichen Aristokratie sind wir heute vergleichsweise gut unterrichtet, auch wenn noch viele Arbeiten nötig sind, um den westeuropäischen Standard zu erreichen ${ }^{14}$.

Der Analyse der spezifisch ,bürgerlichen` Werteordnung, deren allmähliche Ausformung seit dem späten Mittelalter als unkontrovers erscheint, haben sich marxistische Forscher betont im Rahmen der These der sogenannten ,frühbürgerlichen Revolution zugewandt ${ }^{15}$; ,Bürgertum ${ }^{6}$ und ,Bürgerlichkeit' finden seit langem auch das Interesse

${ }^{9} \mathrm{Vgl}$. Otto Büsch (Hg.), Das Preußenbild in der Geschichte. Protokoll eines Symposiums (Berlin, New York 1981) 34; vgl. auch 39.

${ }^{10} \mathrm{Vgl}$. Paul Münch (Hg.), Ordnung, Fleiß und Sparsamkeit. Texte und Dokumente zur Entstehung der „bürgerlichen Tugenden“ (dtv dokumente 2940, München 1984) 11.

11 Vgl. die in den Anmerkungen 2 und 3 zitierte Literatur.

12 Sie thematisieren in der Regel nur die Höhen und Gipfelpunkte ethischen Handelns, besonders den Bereich der Kardinaltugenden. Nachdrücklich zu verweisen ist allerdings auf Otto Friedrich Bollnow, Wesen und Wandel der Tugenden (Ullstein Buch Nr. 209, Frankfurt a. M., Berlin, Wien 1958 und 1975), der sich mit der Erforschung von Ordnungsliebe, Reinlichkeit, Sparsamkeit, Pünktlichkeit, Arbeitsamkeit und Fleiß jener vernachlāssigten „Reihe eng miteinander zusammenhängender schlichter und einfacher Tugenden“ zuwendet, "die für den Aufbau des alltäglichen praktischen Lebens von besonderer Wichtigkeit sind“ (31).

${ }^{13}$ Günter Eifler (Hg.), Ritterliches Tugendsystem (Wege der Forschung 56, Darmstadt 1970). Vgl. hierzu jetzt Joachim Buncke, Höfische Kultur. Literatur und Gesellschaft im hohen Mittelalter (Bd. 2, München 1986) 416f.

${ }_{14}$ Vgl. insbesondere die Arbeiten von Lawrence Stone, The crisis of the Aristocracy 1558-1641 (London 1967) und The family, sex and marriage in England 1500-1800 (London 1977); vgl. für Deutschland Otto Brunner, Adeliges Landleben und europäischer Geist (Salzburg 1949), sowie die exzellente Arbeit von Heinz Reif, Westfälischer Adel 1770-1860. Vom Herrschaftsstand zur regionalen Elite (Kritische Studien zur Geschichtswissenschaft 35, Göttingen 1979).

${ }^{15}$ Gerbard Brendler $(\mathrm{Hg}$.), Die frühbürgerliche Revolution in Deutschland. Referat und Diskussion zum Thema Probleme der frühbürgerlichen Revolution in Deutschland 1476-1535 (Berlin 1961); Rainer Woblfeil (Hg.), Reformation oder frühbürgerliche Revolution? (München 1972); Josef Foschepoth, Reformation und Bürgerkrieg im Geschichtsbild der DDR (Berlin 1976); Adolf Laube, Max Steinmetz, Günter Vogler, Illustrierte Geschichte der frühbürgerlichen Revolution (Berlin, Köln 1982). 
verschiedener wissenschaftlicher Disziplinen in der Bundesrepublik, ohne daß die Problematik bislang interdisziplinär überzeugend bewältigt worden wäre ${ }^{16}$. Über die mentalen Orientierungssysteme des ,Kleinbürgertums', des Handwerks, besitzen wir inzwischen eine Reihe brauchbarer sozialhistorischer Studien ${ }^{17}$.

Gegenüber der Erforschung der Wertewelten von Adel und Bürgertum, die allerdings noch dringend weiterer Differenzierung bedarf, erscheint der weite Bereich der bäuerlichen sowie der unterbäuerlichen und unterbürgerlichen Schichten noch immer vernachlässigt ${ }^{18}$. Der lautstarke Ruf nach einer Erforschung der ,culture populaire auf

${ }^{16}$ Wolfgang Martens, Die Botschaft der Tugend. Die Aufklärung im Spiegel der deutschen Moralischen Wochenschriften (Stuttgart 1968); Leo Balet, E. Gerbard, Die Verbürgerlichung der deutschen Kunst, Literatur und Musik im 18. Jahrhundert, 1936 (Berlin 1973); Dieter Kimpel, Der Roman der Aufklärung (Stuttgart 1967); Alois Wierlacber, Das bürgerliche Drama. Seine theoretische Begründung im 18. Jahrhundert (München 1968); Jürgen Habermas, Strukturwandel der Öffentlichkeit. Untersuchungen zu einer Kategorie der bürgerlichen Gesellschaft (Frankfurt a. M. ' 1971); Manfred Riedel, Art. ,Bürger, Staatsbürger, Bürgertum', in: Otto Brunner, Werner Conze, Reinbart Koselleck (Hgg.), Geschichtliche Grundbegriffe (1. Bd., Stuttgart 1972) 672-725; Ders., Art. ,Gesellschaft, bürgerliche', in: ebenda (Bd. 2, Stuttgart 1975) 719-801; Karl S. Gutbke, Das deutsche bürgerliche Trauerspiel (Stuttgart 1972); Rolf Engelsing, Der Bürger als Leser. lesergeschichte in Deutschland 1500-1800 (Stuttgart 1974); Bettina Hurrelmann, Jugendliteratur und Bürgerlichkeit. Soziale Erziehung in der Jugendliteratur der Aufklärung am Beispiel von Christian Felix Weißes „Kinderfreund“ 1776-1782 (Paderborn 1974); Gert Mattenklott, Klaus R. Scherpe (Hgg.), Westberliner Projekt: Grundkurs 18. Jahrhundert. Die Funktion der Literatur bei der Formierung der bürgerlichen Klasse Deutschlands im 18. Jahrhundert (2 Bde., Kronberg 1974); Gerbart von Graevenitz, Innerlichkeit und Öffentlichkeit. Aspekte Deutscher ,bürgerlicher' Literatur im frühen 18. Jahrhundert, in: DVjs 49 (1975); Franklin Kopitzsch ( $\mathrm{Hg}$.), Aufklärung, Absolutismus und Bürgertum in Deutschland (München 1976); Ursula A. J. Becher, Politische Gesellschaft. Studien zur Genese bürgerlicher Öffentlichkeit in Deutschland (Göttingen 1978); Rudolf Vierhaus (Hg.), Bürger und Bürgerlichkeit im Zeitalter der Aufklärung (Heidelberg 1981); Wolfgang Ruppert, Bürgerlicher Wandel. Studien zur Herausbildung einer nationalen deutschen Kultur im 18. Jahrhundert (Frankfurt a. M., New York 1981); Ulrich Hermann (Hg.), Die Bildung des Bürgers. Die Formierung der bürgerlichen Gesellschaft und die Gebildeten im 18. Jahrhundert (Weinheim, Basel 1982); Peter Schleuning, Das 18. Jahrhundert: Der Bürger erhebt sich (Geschichte der Musik in Deutschland, rororo 7792, Reinbek 1984); Jürgen Kocka (Hg.), Bürger und Bürgerlichkeit im 19.Jahrhundert (Göttingen 1987).

${ }_{17}$ Wolfram Fischer, Rudolf Stadelmann, Die Bildungswelt des deutschen Handwerkers um 1800. Studien zur Soziologie des Kleinbürgers im Zeitalter Goethes (Berlin 1955); Helmut Möller, Die kleinbürgerliche Familie im 18. Jahrhundert. Verhalten und Gruppenkultur (Berlin 1969); Michael Stürmer $(\mathrm{Hg}$.), Herbst des alten Handwerks. Quellen zur Sozialgeschichte des 18. Jahrhunderts (dtv dokumente 2914, München 1979); Andreas Grießinger, Das symbolische Kapital der Ehre. Streikbewegungen und kollektives Bewußtsein deutscher Handwerksgesellen im 18. Jahrhundert ( Frankfurt a.M. u.a. 1981).

16 Vgl. jedoch Karl Sigismund Kramer, Bauern und Bürger im nachmittelalterlichen Franken (Würzburg 1957) und seine Studien zum ,Volksleben' in Bamberg, Coburg und Würzburg; Werner Danckert, Unehrliche Leute. Die verfemten Berufe (Bern, München 1963); G. M. Foster, Peasant Society and the image of limited good, in: American Anthropologist 67 (1965) 293-315; Erich Mascbke, Jürgen Sydow (Hgg.), Gesellschaftliche Unterschichten in den südwestdeutschen Städten (Stuttgart 1967); Hermann Hörger, Kirche, Dorfreligion und bäuerliche Gesellschaft. Strukturanalysen zur gesellschaftsgebundenen Religiosität ländlicher Unterschichten des 17.-19. Jahrhunderts, aufgezeigt an bayrischen Beispielen (München 1978); Rolf Engelsing, Zur Sozialgeschichte deutscher Mittel- und Unterschichten (Kritische Studien zur Geschichtswissenschaft 4, 
der Basis eines expandierten Kulturbegriffs ${ }^{19}$ darf nicht darüber hinwegtäuschen, daß man hier noch weithin am Anfang steht. ,Die Welt eines Müllers um $1600^{20}$, der Prozeß gegen eine Landfahrerfamilie im Jahre $1600^{21}$, die Analysen der Lebenswelten von Räubern und Vaganten ${ }^{22}$, die Untersuchung von Spinnstuben ${ }^{23}$, Charivari ${ }^{24}$, Festen ${ }^{25}$ und weiteren farbigen Ritualen der ,popular culture" sind noch kaum mehr als erste ,Spuren in die Geschichte einer anderen Zivilisation" (Norbert Schindler) ${ }^{\mathbf{2 6}}$, deuten

Göttingen 1973); Edward P. Thompson, Plebeische Kultur und moralische Ökonomie. Aufsātze zur englischen Sozialgeschichte des 18. und 19. Jahrhunderts (Frankfurt a.M., Berlin, Wien 1980); Michael Mitterauer, Lebensformen und Lebensverhältnisse ländlicher Unterschichten, in: Herbert Matis $(\mathrm{Hg}$.), Von der Glückseligkeit des Staates. Staat, Wirtschaft und Gesellschaft in Österreich im Zeitalter des aufgeklärten Absolutismus (Berlin 1981) 325-339; Wolfram Fischer, Armut in der Geschichte. Erscheinungsformen und Lösungsversuche der „Sozialen Frage“ in Europa seit dem Mittelalter (Göttingen 1982).

${ }^{19}$ Peter Burke, Helden, Schurken, Narren: Europäische Volkskultur in der Frühen Neuzeit (Stuttgart 1981); Robert Muchembled, Kultur des Volks - Kultur der Eliten: Die Geschichte einer erfolgreichen Verdrängung (Stuttgart 1982).

${ }^{20}$ Carlo Ginzburg, Der Käse und die Würmer. Die Welt eines Müllers um 1600 (Frankfurt a. M. 1979).

${ }_{21}$ Michael Kunze, Der Prozeß Pappenheimer (Ebelsbach 1981); Ders., Straße ins Feuer. Vom Leben und Sterben in der Zeit des Hexen-Wahns, dargestellt am Schicksal der Landfahrer-Familie Pappenheimer/ ihrer Freunde und Leidens-Genossen/ die im Jahr 1600 in die Fānge der Obrigkeit gerieten (Knaur 1189, München 1982).

${ }^{22}$ Friedrich Christian Benedict Avé = Lallemant, Das deutsche Gaunerthum in seiner socialpolitischen, literarischen und linguistischen Ausbildung zu seinem heutigen Bestande (1-4, Leipzig 1858/1862); Carsten Küther, Räuber und Gauner in Deutschland (Göttingen 1976); Angelika Kopečny, Fahrende und Vagabunden. Ihre Geschichte, Überlebenskünste, Zeichen und Straßen (Berlin 1980); Carsten Küther, Menschen auf der Straße. Vagierende Unterschichten in Bayern, Franken und Schwaben in der zweiten Hälfte des 18. Jahrhunderts (Kritische Studien zur Geschichtswissenschaft, Göttingen 1983); Ernst Schubert, Arme Leute, Bettler und Gauner im Franken des 18. Jahrhunderts (Neustadt a.d. Aisch 1983); vgl. auch die Thematik der Sektion 20 der 35. Versammlung deutscher Historiker in Berlin vom 3.-7. Okt. 1984 (Unterwegssein im Mittelalter). (Stuttgart 1985) 188-192; Adalbert Nagel, Armut im Barock. Die Bettler und Vagunten Oberschwabens (Weingarten 1986).

${ }^{23}$ Hans Medick, Spinnstuben auf dem Dorf. Jugendliche Sexualkultur und Feierabendbrauch in der ländlichen Gesellschaft der frühen Neuzeit, in: Gerbard Huck $(\mathrm{Hg}$.), Sozialgeschichte der Freizeit. Untersuchungen zum Wandel der Alltagskultur in Deutschland (Wuppertal 1980), mit Literatur.

${ }^{24}$ Helga Ettenbuber, Charivari in Bayern. Das Miesbacher Haberfeldtreiben von 1893, in: Richard von Dülmen (Hg.), Kultur der einfachen Leute (München 1983) 180-297 und 250-257 (Literatur).

${ }^{23}$ Roger Chartier, Phantasie und Disziplin. Das Fest in Frankreich vom 15. bis 18. Jahrhundert, in: Richard van Dülmen, Norbert Schindler (Hgg.), Volkskultur. Zur Wiederentdeckung des vergessenen Alltags (16.-20. Jahrhundert) 153-176 und 412-414 (Literatur); Beate Heidrich, Fest und Aufklärung. Der Diskurs über die Volksvergnügungen in bayerischen Zeitschriften (1765-1815). (Münchener Beiträge zur Volkskunde 2, München 1984); Paul Münch, Volksfest und Aufklärung, in: 35. Versammlung deutscher Historiker in Berlin vom 3.-7. Okt. 1984 (Stuttgart 1985) 85 f.; vgl. demnāchst auch Dieter Düding, Peter Friedemann, Paul Münch (Hgg.), Öffentliche Festkultur. Politische Feste in Deutschland von der Aufklärung bis zum ersten Weltkrieg (Reinbek 1988).

${ }^{26}$ So der Titel der Einleitung des in Anm. 25 genannten Sammelbandes von Richard van Dülmen und Norbert Scbindler. 
den intendierten Perspektivenwechsel bislang eher an, als daß sie ihn bereits einzulösen vermöchten ${ }^{27}$.

Jenseits dieser Ansätze zu einer schichtenspezifischen historischen Wertforschung, die freilich nicht immer sozialgeschichtlich konsequent verfährt, mangelt es gegenwärtig noch weithin am Versuch einer umfassenden Zusammenschau der unterschiedlichen Wertewelten. Sie steht intentional im Horizont der Alltagsforschung ${ }^{28}$, deren Gegenstand und Methoden gegenwärtig allerdings noch höchst kontrovers diskutiert werden ${ }^{29}$. Kindheit und Jugend ${ }^{30}$ als autonome Phasen mit eigenen Wertorientierungen erfahren seit kurzem eine schichtenvergleichende Aufmerksamkeit ${ }^{31}$. Auch Haus und Familie stehen schon geraume Zeit im Interessenhorizont der Forschung $^{32}$, ganz im Gegensatz zu den das Haus übergreifenden Sozialgruppierungen der Freundschaft ${ }^{33}$ und Nachbarschaft ${ }^{34}$. Das Gemeinschaftsleben von Frauen, ,Frauenräume' als autonome Wertewelten, entdeckt man eben erst ${ }^{35}$; der aus der Frauenforschung herauswachsende Ansatz einer geschlechterspezifischen Betrachtungsweise ${ }^{36}$ wird künftig auch die parallele Erforschung von ,Männerräumen' als notwendig erscheinen lassen.

Die den historischen Epochen meist unausgesprochen und selten analytisch reflektiert zugrunde gelegten handlungsrelevanten Weltbilder scheinen systematisch noch kaum thematisiert, wenn man von den idealtypischen Klassifizierungsversuchen der

${ }^{27}$ Die besten neuen Ansätze sind in den beiden von Richard van Dülmen publizierten Sammelbänden zu finden (vgl. Anm. 24 und 25).

${ }^{28}$ Jürgen Kuczynski, Geschichte des Alltags des deutschen Volkes (5 Bde., Köln 1980-82).

${ }^{29}$ Vgl. 35. Versammlung deutscher Historiker in Berlin vom 3.-7. Okt. 1984 (Stuttgart 1985) 249f. ("Geschichte von unten - Geschichte von innen“ - Kontroversen um Alltagsgeschichte). ${ }^{30}$ Ulrich Herrmann, Susanne Renftle, Lutz Roth, Bibliographie zur Geschichte der Kindheit, Jugend und Familie (München 1980).

${ }^{11}$ Irene Hardach-Pinke, Gerd Hardach (Hgg.), Kinderalltag. Deutsche Kindheiten in Selbstzeugnissen 1700-1900 (Reinbek 1981); Jürgen Scblumbobm (Hg.), Kinderstuben. Wie Kinder zu Bauern, Bürgern und Aristokraten wurden. 1700-1800 (dtv dokumente 2933, München 1983).

${ }^{32} \mathrm{Vgl}$. die in Anm. 30 genannte Bibliographie.

${ }^{33}$ Wolfdietrich Rasch, Freundschaftskult und Freundschaftsdichtung im deutschen Schriftum des 18. Jahrhunderts vom Ausgang des Barock bis zur Aufklärung (Halle 1936); Klaus Lankbeit, Das Freundschaftsbild der Romantik (Heidelberg 1952); Alexander von Gleichen-Russwurm, Über die Freundschaft. Psychologie, Geschichte und Wandlungen eines Ideals (Bem ${ }^{2} 1971$ ); Friedrich Heinrich Tenbruck, Freundschaft. Ein Beitrag zur Soziologie der persönlichen Beziehungen, in: Kölner Zeitschrift für Soziologie und Sozialpsychologie 16 (1964) 431-456; R. Brain, Freunde und Liebende. Zwischenmenschliche Beziehungen im Kulturvergleich (Frankfurt a.M. 1978).

${ }^{34}$ Vgl. Paul Münch, Kirchenzucht und Nachbarschaft. Zur sozialen Problematik des calvinistischen Seniorats um 1600, in: Ernst Walter Zeeden, Peter Thaddäus Lang (Hgg.), Kirche und Visitationen. Beiträge zur Erforschung des frühneuzeitlichen Visitationswesens in Europa (Stuttgart 1984) $242 \mathrm{f}$. (Auswahl-Bibliographie in Anm. 148).

35 35. Versammlung deutscher Historiker in Berlin vom 3.-7. Okt. 1984 (Stuttgart 1985) 58-61 (,Frauenräume“).

${ }^{36}$ Gisela Bock, Historische Frauenforschung: Fragestellungen und Perspektiven, in: Karin Hausen, Frauen suchen ihre Geschichte. Historische Studien zum 19. und 20. Jahrhundert (München 1983) 22-60; Dies., Der Platz der Frauen in der Geschichte, in: Neue Ansätze in der Geschichtswissenschaft (Conceptus-Studien 1). (Wien 1984) 108-127. 
Soziologen, von Max Weber bis Pierre Bourdieu ${ }^{37}$, absieht. Dieser Befund trifft besonders auf die sog. ,Frühe Neuzeit' zu, jene über 300jährige Zwischenperiode zwischen Mittelalter und Moderne, deren Komplexität jede vorschnelle Synthese verbietet. Ihr charakteristischer Zuschnitt als Übergangsepoche und - was gegenwärtig oft vernachlässigt wird - als eigenständige Periode mit unverwechselbaren Konturen erweist sich als höchst widerständig gegen allzu glatte Einordnungen ${ }^{38}$. Der Weg von der ,mittelalterlichen res publica Christiana zum Mächte-Europa der Neuzeit ${ }^{639}$, der facettenreiche Prozeß politischer Parzellierung, dem eine Territorialisierung der sozialen und mentalen Strukturen parallel geht, ergibt insgesamt ein Tableau enormer Komplexitāt. Die stabile Ständegesellschaft des Mittelalters, falls es das überhaupt je gegeben hat, die in den ,drei Ordnungen“ sich angeblich widerspiegelnde Realität des gesellschaftlichen Baus der media aetas erscheint demgegenüber als relativ überschaubar und suggeriert, wenn man die detaillierten Spezialstudien zu den ,trois ordres' anschaut, das Bild einer bereits weitgehend vermessenen Landschaft ${ }^{40}$. Ein vergleichbarer Forschungsstand läßt sich für die Frühe Neuzeit nicht vermelden. Weder sind die in wachsender Differenzierung begriffenen Vorstellungen der Zeitgenossen von der Struktur ihrer Gesellschaft aufgearbeitet, die drei-, vier- und mehrgliedrigen Modelle auch nur erfaßt ${ }^{41}$, noch ist die den differierenden Gesellschaftsimaginationen korrespondierende Gesellschaftsrealität hinlänglich analysiert - zu schweigen von den Problemen einer angemessenen Beschreibung der Úbergangsepoche ,gewesener Stände' und ,ungeborener Klassen' zu Ende des 18. Jahrhunderts.

Soweit erkennbar, hat bisher nur Heinrich Lutz versucht, in umfassendem Zugriff das Normengefüge und den gesellschaftlichen Wandel zwischen Renaissance und Revolution explizit zu thematisieren. Er tut dies unter den Stichworten ,Differenzierung und Säkularisierung', gelangt zu einer Unterscheidung in Makro- und Mikronormen und handelt sein Thema exemplarisch am ,Problem der Staatsräson' und dem Verhältnis von ,Religion und Kapitalismus $\mathbf{a b}^{42}$. Das alltägliche Funktionieren von,Grundwerten in der Reichsstadt im Spätmittelalter und in der Frühen Neuzeit' hat Hans Christoph Rublack in einer idealtypisierenden, behutsamen Interpretation herausgear-

${ }^{37}$ Max Weber, Wirtschaft und Gesellschaft. Grundriss der verstehenden Soziologie (Tübingen ${ }^{5} 1980$ ); Pierre Bourdieu, Zur Soziologie der symbolischen Formen (Frankfurt a. M. 1974).

${ }^{38}$ Johannes Burkhardt, Frühe Neuzeit. 16.-18. Jahrhundert (Grundkurs Geschichte 3, Königstein 1985) 21.

${ }^{39}$ Josef Engel in: Theodor Schieder $(\mathrm{Hg}$.$) , Handbuch der europäischen Geschichte (Bd. 3, Stuttgart$ 1971) 1-443.

${ }^{40}$ Georges Duby, Les trois ordres ou l'imaginaire du féodalisme (Paris 1978); vgl. hierzu Otto Gerhard Oexle, Die, Wirklichkeit' und das, Wissen'. Ein Blick auf das sozialgeschichtliche CEuvre von Georges Duby, in: HZ 232 (1981) 61-91; vgl. auch den Beitrag von Otto Gerbard Oexle in diesem Band.

${ }^{11}$ Wie irreführend es schon ist, Martin Luther auf das Dreistände-Modell zu reduzieren, hat Günter Vogler in seiner Kritik an Thomas A. Brady überzeugend gezeigt. Vgl. Günter Vogler, Luther und die Gesellschaft, in: Lutherjahrbuch 52 (1985) 230-238.

${ }^{42}$ Heinrich Lutz, Normen und gesellschaftlicher Wandel zwischen Renaissance und Revolution

- Differenzierung und Säkularisierung, in: Saeculum 26 (1975) 166-180. 
beitet. Friede, Recht, Gemeinnutz werden sowohl in ihrer integrativen Funktion als auch in ihrer ideologischen Vereinnahmung durch Gruppeninteressen vorgestellt ${ }^{43}$. Der jüngste einschlägige Beitrag zur Thematik stammt von Winfried Schulze, der unter der Überschrift ,Vom Gemeinnutz zum Eigennutz، dem ,Normenwandel in der ständischen Gesellschaft der Frühen Neuzeit" an einem der zentralen Begriffspaare der Epoche nachgeht ${ }^{44}$. Rublacks resigniertem Statement bezüglich des in seinem Bereich höchst defizitären Forschungsstandes ist voll zuzustimmen: „Die Frage nach den in Städten zur Geltung gebrachten Werten, die das Zusammenleben sicherten, ist, sieht man von vereinzelten Untersuchungen zum Gemeinen Nutzen oder zu den Schlagworten des Bauemkriegs ab, kaum gestellt, noch gar grundlegend und gesichert aufgearbeitet - ein eigenartiger Sachverhalt. Denn es gab ja diese Werte in der Stadt.“43

In der Tat, es gab diese Werte. Und sie waren nicht nur in der Stadt präsent, sondern ebenso in allen übrigen sozialen Gruppierungen, vom ,ganzen Haus', der Nachbarschaft, den Gilden, Brüderschaften und Zünften, den Dorf- und Kirchengemeinden bis hin zum Kosmos der Klöster oder Fürstenhöfe - schwerer faßbar auch in den informelleren Gruppen der Bettler, der Räuberbanden, der wechselnden Verbindungen der Pilger und Vaganten. Vielleicht ist es während der Frühen Neuzeit auch schon zur Ausbildung übergreifender territorialstaatlicher Wertecodices oder zur Formierung eines spezifisch ,teutschen Wertekanons gekommen - die plakativ-moralisierende Ausmalung der Nationalcharaktere, des ,Naturells der Völcker ${ }^{46}$, weist in diese Richtung.

Die Erforschung der Wertewelten unterschiedlicher Sozialgruppen, von den relativ festgefügten Wertesystemen der sozialen Geburts- oder Berufsstände bis hin zu den Orientierungssystemen der ,unehrlichen' und unterständischen Schichten, läßt sich gegenwärtig nur als Forschungsdesiderat formulieren. Nachdem der verbreitete, vulgärmarxistische Ansatz, menschliches Verhalten ausschließlich als Spiegelung der materiellen Lage, den sogenannten ,Úberbau' generell als kausale Resultante oder Produkt des ökonomischen ,Unterbaus' anzusehen, zur Erklärung unterschiedlichen menschlichen Verhaltens bei gleicher Ausgangslage versagt, erscheint es allerdings dringend notwendig, sich ergänzend der Erforschung anderer handlungsrelevanter Faktoren zuzuwenden. „Offenbar ist da etwas“ - so kürzlich Hagen Schulze mit Blick

${ }^{43}$ Hans-Cbristoph Rublack, Grundwerte in der Reichsstadt im Stpātmittelalter und in der Frühen Neuzeit, in: Horst Brunner $(\mathrm{Hg}$ ), Literatur in der Stadt. Bedingungen und Beispiele städtischer Literatur des 15.-17. Jahrhunderts (Göppingen 1982) 9-36; ders., Political and Social Norms in Urban Communities in the Holy Roman Empire, in: Kaspar von Greyerz (Hg.), Religion, Politics and Social Protest. Three Studies on early Modern Germany (London 1984) 24-60.

44 Winfried Schulze, Vom Gemeinnutz zum Eigennutz. Uber den Normenwandel in der ständischen Gesellschaft der Frühen Neuzeit, in: HZ 243 (1986) 591-626.

${ }^{45}$ Hans-Christoph Rublack, Grundwerte (wie Anm. 43) 12.

"6obann Heinrich Zedler, Grosses Vollständiges Universal-Lexikon (Bd. 25, Leipzig/Halle 1740) Sp. 1246-1251; eine illustrative Völkertafel vom Anfang des 18. Jahrhunderts charakterisiert der Reihe nach je einen Vertreter der wichtigsten europäischen Staaten: „Spanier, Frantzoß, Wälisch, Teutscher, Engerländer, Schwöth, Boläck, Unger, Muskawith, Tirk oder Griech“. Eine (Schwarzweiß-)Abbildung der farbigen Tafel in: Die Türken vor Wien - Europa und die Entscheidung an der Donau 1683 (Wien $\left.{ }^{2} 1983\right) 266$. 
auf die französische Histoire des mentalités -, „das sich zwischen materielle Ursachen und gesellschaftliches Verhalten schiebt: das Feld der persönlichen und der kollektiven Subjektivität, der politischen Kulturen, der Weltbilder und Meinungsklimate“, jene "atmosphère mentale“, jene „großenteils vorbewußten Einstellungen gesellschaftlicher Gruppen, die unbefragten Axiome und Normen, die Grundhaltungen und Gesinnungen die die menschliche Gemeinschaft stiften "47?

Die Menschen der Frühen Neuzeit haben bereits von diesen das menschliche Handeln oft verborgen steuernden, jedoch fraglos geschichtsmächtigen Kräften gewußt und sie im Begriff der ,Sitten' zu fassen gesucht - man denke nur an Voltaires „Histoire de l'esprit et des mœurs'. Die Veränderung der ,Sitten' geschehe „unvermerckt", meint Zedler, wir würden die Mutation erst gewahr, wenn sie geschehen sei, weswegen manche Gelehrte zur Erklärung dieses Phänomens die Existenz eines ,genius seculi“ angenommen hätten. Die ,Sitten' als Sammelbegriff der nach Stand, Vermögen oder Lebensart je differierenden Lebensformen, die ,Sitten“ als Begriff des ,Thun und Lassens selbst' sowie der ,äusserlichen Beschaffenheit des Thun und Lassens $^{\mathbf{4 8}}$ - diese Definitionen nehmen vieles vorweg, was man heute mit dem modischen Begriff der ,Mentalität' meint.

Es ist keine Frage, daß sich eine Geschichte solcher ,Sitten' oder Mentalitāten mit dem klassischen Quellenfundus der Geschichtswissenschaft nicht schreiben läßt. Die amtlichen oder offiziösen Dokumente der politischen und kirchlichen Administrationen spiegeln in der Regel nur die Sollebene, also das durch Normen intendierte Verhalten - ,Norm' hier mit Rüdiger Lautmann verstanden als vorgeschriebener, sanktionierter und allgemein geltender Verhaltensstandard ${ }^{49}$.

Um den ,Werten', jenen den Normen übergeordneten Orientierungseinrichtungen einer Gesellschaft, die - laut Claessens - „mehr oder weniger objektiviert als äußere Leit- und Richtlinien wirken, teils im Individuum internalisiert ihre Befolgung erzwingen" ${ }^{\text {"so }}$ - um solchen Verhaltensleitbildern auf die Spur zu kommen, bedarf es eines extrem weiten, tendenziell nach allen Seiten offenen Quellenbegriffs. Zur Quelle taugt und muß hier alles taugen, was Kenntnis der Wertevergangenheit vermittelt, um eine alte Quellendefinition zu variieren.

Die vorangegangenen, nach vielen Seiten ergänzungsbedürftigen Überlegungen zum Forschungsstand zeigen, wie wenig systematisch bislang die Wertorientierungen der frühneuzeitlichen Ständegesellschaft reflektiert worden sind. Wer sich die differenzierten Lebens- und Wertewelten der Frühen Neuzeit vor Augen führt, der muß in

${ }^{47}$ Hagen Schulze, Mentalitätsgeschichte - Chancen und Grenzen eines Paradigmas der französischen Geschichtswissenschaft, in: GWU 1985, 248.

${ }^{48}$ Grosses Vollständiges Universal-Lexikon (Bd. 37, Leipzig/Halle 1743) Sp. $1747 \mathrm{f}$.

49 Wert und Norm (wie Anm. 7) 108.

so Dieter Claessens, Familie und Wertsystem (Soziologische Abhandlungen 4, Berlin $\left.{ }^{3} 1972\right) 35$. 
der Tat ernsthaft fragen, ob sich über dem erst ansatzweise entwirrbaren Neben- und Miteinander individueller und gruppenspezifischer Wertorientierungen, die durchaus nicht nur in immobiler Statik, sondern ebenso in dynamischer Wandlung begegnen können ${ }^{31}$, überhaupt ein Kanon von Grundwerten ausmachen läßt, an dem die darunterliegenden, weit ausdifferenzierten Werte- und Normensysteme in irgendeiner Weise partizipieren. Hypothetisch lassen sich eine Reihe von Gegensatzpaaren aufstellen, die in vielen historischen Darstellungen als quasi stabile Größen im Geschichtsprozeß, als meist unreflektiert vorausgesetzte Grundwerte begegnen, denen geradezu epochale Qualitäten zugeschrieben werden. Weitgehender Konsens herrscht beispielsweise darüber, daß während der Frühen Neuzeit eine zuvor angeblich fundamental von christlichen Normen beherrschte Welt, eben jene viel beschworene, res publica Christiana', in einem langsamen, aber unaufhaltsamen Säkularisierungsproze $\beta$ dechristianisiert worden sei. Dieses Interpretament mag den Zerfall der einheitlichen Theologie des Mittelalters, falls es eine solche überhaupt je gegeben hat, die Entstehung konkurrierender christlicher Konfessionen und die Ablösung des christlichen Vorsehungsglaubens durch das aufklärerische rationale Weltbild geistesgeschichtlich durchaus angemessen beschreiben, es bleibt sprachlos, wenn man sich von den Höhen der Theologie- und Geistesgeschichte hinab in die Niederungen sozial differenter Orientierungssysteme begibt ${ }^{52}$. Mustert man die kirchlichen Visitationsprotokolle ${ }^{53}$, eine der wenigen seriellen Quellen zur ,Religion des Volkes ${ }^{454}$, durch, dann zeigt sich, daß noch um 1600 von einer durchgängig christlichen Orientierung des größten Teils der Bevölkerung keine Rede sein kann. Selbst den Hirten der angeblich christlichen Herde sind die fundamentalen Grundsätze christlicher Dogmatik allzuoft unbekannt, das Kirchenvolk verharrt noch ganz selbstverständlich in vorchristlichen oder allenfalls christlich amalgamierten magischen Praktiken und Riten der Weltbewältigung, die von den Visitatoren regelmäßig als Aberglaube und Teufelswerk denunziert werden - ein Befund, den Jean Delumeau mit der These einer zweiten Christianisierung während des 16. und 17. Jahrhunderts für den Bereich der katholischen Kirche schon lange behauptet ${ }^{55}$ und der sich ohne Schwierigkeiten auf die Situation der evangelischen Kirchen ausdehnen läßt. Man weiß noch sehr wenig von dieser spezifisch bäuerlichen, nur an der Oberfläche christianisierten Religion, deren Spuren Carlo Ginzburg aus den Aussagen des friaulischen Müllers Menocchio rekonstruieren zu können

${ }^{31}$ Vgl. den in Anm. 44 genannten Beitrag von Winfried Schulze.

52 Úberzeugend allerdings: Micbel Vovelle, Piété baroque et déchristianisation en Provence au XVIIIe siècle. Les attitudes devant la mort d'après les clauses testaments (Civilisations et Mentalités, Plon 1973).

${ }^{53}$ Ernst Walter Zeeden, Hansgeorg Molitor (Hgg.), Die Visitation im Dienst der kirchlichen Reform (Münster ${ }^{2} 1977$ ); Ernst Walter Zeeden (Hg.) in Verbindung mit Peter Thaddäus Lang, Cbrista Reinhardt und Helga Scbnabel-Schüle, Repertorium der Kirchenvisitationsakten des 16. und 17. Jahrhunderts in Archiven der Bundestepublik, Bd. 1: Hessen (Stuttgart 1982); Ernst Walter Zeeden, Peter Thaddäus Lang (Hgg.), Kirche und Visitation. Beiträge zur Erforschung des frühneuzeitlichen Visitationswesens in Europa (Stuttgart 1984).

${ }^{54}$ Der Begriff bei Martin Scharfe, Die Religion des Volkes. Kleine Kultur- und Sozialgeschichte des Pietismus (Gütersloh 1980).

${ }^{55}$ Jean Delumeau, Le catholicisme entre Luther et Voltaire (Paris 1971). 
glaubt $^{56}$. Es erscheint nicht ausgeschlossen, daß sich Ginzburgs Befund mit Hilfe neuer Quellen erhärten läßt. In der während des 16. Jahrhunderts oft erzählten Geschichte von den ungleichen Kindern Evas $^{57}$ repräsentiert Kain den ungehorsamen, frechen, störrischen und obendrein schmutzigen Bauern, der, als ihn Gott einer Katechismusprüfung unterzieht, Lehren vertritt, die in manchen Zügen an Menocchios Religion erinnern. In einer Bearbeitung der Geschichte durch Nathan Cytraeus aus dem Jahr 1568 lautet Kains Glaubensbekenntnis: „Ich glaube, dass ein Allmächtiger gott seym, ein Schöpffer der gantzen Welt, welchen man mit Opffer versöhnen soll, auff dass er unsere Ecker fruchtbar mache. Ob er aber der Menschen Gebet erhöre, und die Sünde vergebe, da zweiffele ich gar sehr an. Ob die Seele unsterblich sey, und ein ander Leben nach diesem werde folgen, wil ich alsdenn wol erfahren, wenn ich von diesem Leben abscheyden werde. ${ }^{\text {“58 }}$ In einer Variante der Geschichte, wie sie Johann Baumgarten (Pomarius) 1559 in seinem Katechismus liefert, läßt sich der vordergründige Materialismus Kains noch drastischer fassen. Auf die Frage Gottes, „ob er auch gleube“, anwortet Kain: „Was ich sehe, das gleub ich ja.“ „Ihe“ sagt unser Herrgott, „dein Vater hat dich ja anders gelehrt: Nemlich wie du an Gott und seinen Son, des Weibes Samen, gleuben solt. Wie gott denn für euch und die gantze Welt, zu einem Suhn- und erloess Opffer schlachten will.“ Antwort Cain: „was kan mein Vater, der alte Nar, guts leren, und was sol ich doch dem gleuben können, der gott selbs nicht gegleubet hat. “ [...] Fragt Gott: „Ihe was gleubstu denn?“ Cain: „O wie gerne wuste der Kerl, was ich gleube. O ja bald sagts Cain, oder lests, mein ich.“ Gott: „Ihe, wie wenn ichs denn bereits wuste.“ Cain: „Weistu, warumb fragstu mich denn?" Gott: „Ihe das hier meine lieben Engel, dar deine Mutter, Brüder und Schwesterchen, auch hören mügen, ob du auch den Catechismus kanst und gelernet hast.“ Cain: „Ha, ha, ha. Es ist mir als umb den Catechismus! Gott ehre mir eine gute Scheune mit Korne, die ist mir lieber denn alle Catechismus in der Welt, dar kan ich was ausdreschen. Ich müste lange klopffen, bis mir Korn, Geld und Gut aus dem Catechismo fiele. ${ }^{\text {"59 }}$

Martin Scharfe hat in einem Aufsatz über, Subversive Frömmigkeit' auf die ,Distanz unter Volksklassen zur offiziellen Religion' hingewiesen. Dabei wird deutlich, wie widerständig sich manche Individuen noch bis ins 18. Jahrhundert hinein zu den gültigen kirchlichen Lehren verhielten. 1725 antwortete ein 30jähriger Mann auf die Frage, ,Ob das Heutige Abendmahl nicht das Hailige Abendmahl sey, das Christus ein gesetzt Hat', trotzig und lapidar: „Nein, es sey eine Menschensatzung!“, und auf die Frage, , Ob Wir im Heutigen Abendmahl nicht den Leuten Christi Leib und Blut geben', ebenso sicher und selbstbewußt: „Nichts weniger. Wir geben es nur vor Christi Leib und Blut aus. ${ }^{\text {60 }}$

${ }^{56}$ Wie Anm. 20.

${ }^{57}$ Jobannes Winzer, Die ungleichen Kinder Evas in der Literatur des 16. Jahrhunderts (Greifswald 1908).

${ }^{58}$ Ebd. 35.

s9 Ebd. 39.

${ }^{60}$ Martin Scharfe, Subversive Frömmigkeit. Über die Distanz unterer Volksklassen zur offiziellen Religion. Beispiele aus dem württembergischen Protestantismus des 18. Jahrhunderts, in: Kultur zwischen Bürgertum und Volk (Argument-Sonderbd. 103, 1983) 121. 
Fraglos müßte diese Thematik vertieft werden, um eine wirklich tragfähige Hypothese abzugeben. In den Visitationsprotokollen liegt hierzu ein reicher Quellenfundus bereit. Doch zeigen auch schon diese Beispiele, daß der unter dem Begriff der Säkularisierung behauptete Wandel durchaus nicht alle Schichten der Bevölkerung gleichermaßen betroffen hat. Legt man den von den verschiedenen christlichen Kirchen im Konfessionsbildungsprozeß des 16 . Jahrhunderts ${ }^{61}$ postulierten, in Einzelheiten differierenden Begriff des rechten christlichen Glaubens und Lebens zugrunde - und man kann wohl nur davon ausgehen -, dann zeigt sich, daß der von den Konfessionen intendierte christliche Standard, wenn überhaupt, dann wohl erst im 18. Jahrhundert erreicht wurde. Einer wie immer gearteten ,Dechristianisierung" aber müßte logischerweise eine ,Verchristlichung' vorausgegangen sein, wenn das Säkularisierungsmodell tragfähig sein soll. Man ist in diesem Bereich allzusehr von den normativen Quellen ausgegangen, die allerdings schon seit dem Mittelalter eine durchgehende Christianisierung suggerieren, und man hat außerdem naiv die Verchristlichung der Eliten mit einer allgemeinen Christianisierung verwechselt.

Ebenso fragebedürftig wie das vorgestellte Interpretament, das vom epochalen Wandel einer christlichen zu einer rational-aufgeklärten Weltordnung ausgeht, ist die Annahme, die frühneuzeitliche Gesellschaft sei ein ,stabiler Binnenraum ' gewesen, „in dem sich Anschauungen, Lebensweisen, Sitten im älteren Sinn des Wortes zu festen, das öffentliche Leben leitenden Werten" kondensiert hätten. Auch hier dürfte die Erforschung der höchst differenten Praxis der alltäglichen Lebensformen und Wertorientierungen zu anderen Ergebnissen führen. Nur wenn man vom fraglos weiter pluralisierten und differenzierten 19. und 20. Jahrhundert her argumentiert, kann man als ,Leistung der älteren Gesellschaft deren weitgehende Prägung durch „einheitliche sittliche Auffassungen “62 behaupten - eine problematische Perspektive, der manchmal auch Frühneuzeithistoriker gegenüber dem Mittelalter verfallen.

Nicht weniger diskussionsbedürftig erscheinen weitere vorwissenschaftliche Makrothesen zum historischen Wandel, die sämtlich die Existenz bestimmter Grundwerte implizieren, wie z.B. der angenommene Prozeß fortschreitender Individualisierung (Von der Sozialităt zur Individualităt) ${ }^{63}$, der Prozeß der Zivilisation (Von der grobianischen zur polizierten Gesellschaft) ${ }^{64}$, auch der Prozeß der Rationalisierung (Vom ma-

${ }^{61}$ Ernst Walter Zeeden, Die Entstehung der Konfessionen (München 1965); Wolfgang Reinbard, Gegenreformation als Modernisierung? Prolegomena zu einer Theorie des konfessionellen Zeitalters, in: ARG 68 (1977) 226-251; Peter Thaddäus Lang, Konfessionsbildung als Forschungsfeld, in: HJB 100 (1980) 479-493; Wolfgang Reinbard, Konfession und Konfessionalisierung in Europa, in: Ders. (Hg.), Bekenntnis und Geschichte (München 1981) 165-189; Heinz Schilling, Konfessionskonflikt und Staatsbildung. Eine Fallstudie über das Verhältnis von religiösem und sozialem Wandel in der Frühneuzeit am Beispiel der Grafschaft Lippe (Gütersloh 1981).

${ }^{62}$ Hans Maier, Grundwerte und Grundrechte, in: Ansgar Paus (Hg.), Werte, Rechte, Normen (Graz, Wien, Köln 1979) 94.

${ }^{63}$ Die Individualisierungsthese durchzieht eine unübersehbare Fülle von Werken. Bis heute klassisch: Jacob Burckhardt, Die Kultur der Renaissance in Italien. Die Entdeckung der Welt und des Menschen (zuerst erschienen 1860, Stuttgart 1960).

${ }^{61}$ Norbert Elias, Úber den Prozeß der Zivilisation. Soziogenetische und psychogenetische Untersuchungen (2 Bde., Frankfurt a. M. 1976). 
gischen zum rationalen Weltbild) ${ }^{65}$. Diese Modelle des historischen Wandels sind, wenn man ihre ideologische Funktion zur Legitimation der Moderne nicht teilt, als $g e$ samtgesellschaftlich taugliche Erklärungsinstrumente aus der Diskussion zu verabschieden. Ihre modernisierungstheoretische Basis entlarvt sie als Interpretamente derjenigen Schichten, die den Weg in die Moderne im wesentlichen gebahnt und davon wohl auch am meisten profitiert haben. Die Kostengeschichte der Modernisierung ist noch zu schreiben. Gerhard Oestreichs Interpretament der ,Sozialdisziplinierung' ist ein Anfang, ein Anfang allerdings, der den Paradigmenwechsel bereits deutlich konturiert $^{66}$. In seinem Kontext wäre beispielsweise der fundamentale Wandel des mittelalterlichen Treueverhältnisses, der komplementären Entsprechung von Schutz/Schirm und Rat/Hilfe zur kommenden Dichotomie von Befehl und Gehorsam zu beschreiben. Das geringe gesamtgesellschaftliche Erklärungspotential der genannten Modelle des frühneuzeitlichen historischen Wandels muß allerdings ihre weitere Verwendung nicht grundsätzlich obsolet machen. Als heuristische Hilfsbegriffe dürften sie weiterhin unverzichtbar sein.

Als vorläufiges Fazit ist festzuhalten, daß es schwerfällt, überhaupt einen Kanon von Grundwerten auszumachen, der die Wertewelten der frühneuzeitlichen Individuen und Sozialgruppen möglicherweise zusammengebunden hat. Die von den konkurrierenden Kräften regelmäßig zur Legitimierung ihrer unterschiedlichen Ziele verwandten Schlagworte von Friede, Recht und Gemeinnutz waren sicher im politischen und sozialen Vollzug partiell wirksame Werte, wie Hans Christoph Rublack am Beispiel der Stadt deutlich machen konnte ${ }^{67}$, aber sie waren eben inhaltlich nicht eindeutig gefüllt und konnten deswegen ideologisch zur Durchsetzung sehr unterschiedlicher Interessen eingesetzt werden. Aufgrund ihrer fast beliebigen Funktionalisierung fällt es schwer, sie einem Kanon inhaltlich konsistenter Grundwerte zuzurechnen.

\section{III}

Gab es in der Ständegesellschaft des 16. bis 18.Jahrhunderts also keine Grundwerte, keine gemeinsamen Orientierungen oder Weltbilder, keinen ,genius saeculi', keinen Zeitgeist, der die höchst unterschiedlichen Wertewelten der Individuen und sozialen Gruppen integrierend zusammengebunden hat? Es fällt leicht, zu sagen: Doch, das hat es gegeben. Die Existenz einer zwischen materieller Lage und politisch-sozialem Handeln liegenden Schicht subjektiver oder kollektiver Mentalităt, die beispielsweise während einer Hungersnot den einen Bauern zu einer Wallfahrt, den andern zu aktivem Widerstand angeregt hat, die Handlungsrelevanz einer solchen ,atmosphère mentale' läßt sich kaum bestreiten. Ihre Beschreibung aber bereitet erhebliche Schwierig-

${ }^{65} \mathrm{Zu}$ dieser These Max Webers vgl. Wolfgang Scblucbter, Die Entwicklung des okzidentalen Rationalismus. Eine Analyse von Max Webers Gesellschaftsgeschichte (Tübingen 1979).

${ }^{66}$ Gerbard Oestreich, Strukturprobleme des europäischen Absolutismus, in: VSWG 55 (1968) 329-347.

$67 \mathrm{Vgl.} \mathrm{Anm.} 43$. 
keiten. Während wir über die Weltbilder und Orientierungssysteme der gebildeten Minderheit im Spiegel ihrer literarischen Produktion einige Aussagen machen können, wissen wir noch sehr wenig über die Verhaltensleitbilder der breiten Masse der Bevölkerung. Gab es tatsächlich eine neben der Elitenkultur autonom existierende ,moral economy der Unterschichten ${ }^{68}$, eine ,popular culture', die dem Modernisierungsprozeß der Frühen Neuzeit jedoch nicht standzuhalten vermochte und fast spurlos verschwand? Oder erliegt diese emphatisch-dramatische These von der Zerstörung der ,culture populaire" durch die ,culture des élites' nicht einem allzu simplen dichotomischen Denken, das nicht nur durch die Annahme eines wechselseitigen komplexen Vermittlungszusammenhangs beider Kulturen zu modifizieren wāre, sondern ebenso plausibel durch die Hypothese einer Vielzahl horizontal und vertikal in unterschiedlicher Dichte verknüpfter ,Kulturen' ersetzt werden könnte?

Sobald man sich auf die Suche nach Wertorientierungen begibt, an denen möglicherweise alle Bevölkerungsschichten in irgendeiner Weise partizipierten, wird das Dilemma offenbar. Stellt man etwa die Frage, welches Bild sich die Zeitgenossen des 16. bis 18. Jahrhunderts von der Struktur ihrer Gesellschaft gemacht haben, dann fällt es nicht schwer, die in Schriften oder Bildern veröffentlichte Meinung vom rechten Bau der ,societas humana zu beschreiben. Als Grundkategorie der gesamten Gesellschaftsstruktur erscheint der Begriff der Ordnung. „Nichts ist schöner, nichts ist fruchtbarer als die Ordnung. Die Ordnung verschafft auf dem riesigen Theater dieser Welt allen Dingen Wert und Rang. Die Ordnung ist in der Kirche Gottes der Nerv des Corpus mysticum. Die Ordnung ist das stārkste Band im Staats- und Familienleben. Und im wissenschaftlichen Leben haucht die Ordnung den Lehr- und Lerngegenständen die Seele ein.“ So leitete Johann Heinrich Alsted seine im Jahre 1630 erschienene Enzyklopädie ein ${ }^{69}$. „Nihil pulchrius ordine ${ }^{470}$ - , nichts ist besser als Ordnung, die wirre Regellosigkeit hat noch stets geschadet, und ,alles hat seine feste Ordnung durch die Zahlen" "71 - diese Anschauung durchzieht die gesamte Frühe Neu-

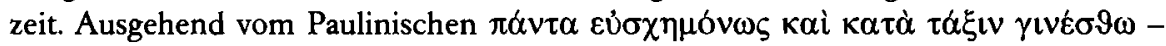
lasset alles ehrlich und ordentlich zugehen' (1. Kor. 14,40), regulierte ,Ordnung' nicht nur die kirchlichen Verfassungsstrukturen ${ }^{72}$, ihr wurde darüber hinaus der Rang einer fundamentalen Gesellschaftskategorie zugesprochen: „Was aber in policeien und gemeiner bürgerlichen regirung, in haushaltung, allerlei künsten und hantirungen, in reden, schreiben, lesen, leren, lernen und was dergleichen ist, ordnung für eine sonderli-

${ }^{68} \mathrm{Vgl}$. die in Anm. 19 genannte Literatur; außerdem aus Anm. 18 die Aufsatzsammlung von Edward P. Thompson.

${ }^{69}$ Encyclopaedia septem tomis distincta (Herbornae Nassoviorum 1630). Übersetzung bei Erich Trunz, Der deutsche Spãthumanismus um 1600 als Standeskultur, in: Richard Alewyn (Hg.), Deutsche Barockforschung, Dokumentation einer Epoche (Köln, Berlin 1966) 147.

${ }^{70}$ Olivier Fatio, Nihil Pulchrius Ordine. Contribution a l'étude de l'établissement de la discipline ecclésiastique aux Pays-Bas ou Lambert Daneau aux Pays-Bas (1581-1583). (Kerkhistorische Bijdragen II, Leiden 1971).

${ }^{71}$ Aus der subscriptio eines Emblems des Joannes Sambucus (1566). In: Paul Münch (Hg.), Ordnung, Fleiß und Sparsamkeit (wie Anm. 10) 77.

${ }^{2}$ Paul Münch, Zucht und Ordnung. Reformierte Kirchenverfassungen im 16. und 17. Jahrhundert (Nassau-Dillenburg, Kurpfalz, Hessen-Kassel). (Stuttgart 1978) 183-189. 
che kraft habe, ist weitleuftig zu erzelen nicht vonnöten. Es gibt die gemeine erfarung, daß alle hendel, damit die menschen umbgehen, leichtlicher, glücklicher und fruchtbarlicher fürgenommen und volnzogen werden von denen, so ordnung verstehen und halten, denn von denen, die es für gleich achten, ob etwas zuerst oder am letzten, fornen, hinten und mitten gesetzt oder gehandlet werde. ${ }^{\text {“73 }}$ Der Begriff der ,Ordnung meinte in erster Linie eine statische, hierarchisch gestufte Ordnung; den Mikrokosmos der societas humana dachte man sich als Spiegelbild des Makrokosmos ${ }^{\mathbf{7 4}}$. Entsprechend zeigten „alle Gebiete des Lebens [...] eine große, gottgewollte Ordnung: die Tugenden und Sünden in ihren vielfältigen Abstufungen; die Bindungen von Mensch zu Mensch, die auf die Urformen der ,Hausstände ${ }^{6}$ - Hausvater, Hausmutter, Kinder, Verwandte, Freunde, Gesinde - zurückgingen; der Staat mit den staatsrechtlichen Ständen - Fürsten, Adel, Städtern, Bauern - und der Stufung von Obrigkeit und Untertan; das verschachtelte Rangsystem der Wissenschaften und Künste mit den Instrumentalwissenschaften als Grundlage, dem Turmbau der Realwissenschaften darüber und der Theologie an der Spitze; die menschlichen Gesellschaftsstände von Kaiser und Fürsten bis zu Bauer und Bettler." ${ }^{\text {"75 }}$

Das Prinzip der hierarchischen Ordnung implizierte das Prinzip der als natürlich oder göttlich gestiftet angesehenen sozialen Ungleichheit ${ }^{76}$. Mit Paulus (Gal. 3, 28) sah man die ethnischen, sozialen und geschlechterspezifischen Unterschiede erst „im geistlichen reich des Herren Christi“" aufgehoben, wo nicht mehr zwischen Jude und Grieche, Knecht und Freiem, Mann und Weib unterschieden werde ${ }^{77}$. Historisch interpretierte man den ungleichen Bau der Gesellschaft als Strafe für den Sündenfall. Die bereits erwähnte Geschichte von den ungleichen Kindern Evas war ein populäres Exempel für die göttliche Einsetzung der hierarchischen Ständeordnung. In einer frühen lateinischen Fassung durch Philipp Melanchthon aus dem Jahre 1539 war die durch Gott vorgenommene "distinctio ordinum noch ganz dem alten dreigliedrigen Schema der ,trois ordres ${ }^{4}$ verhaftet ${ }^{78}:$ Abel und Seht werden zu Priester (sacerdos) und König (rex) befördert, der schmutzige, unzuvilisierte Kain dagegen muß seine Degradierung zum Knecht (servus) in Kauf nehmen, ,ne aut religionem contumelia adficiat, aut conturbet societatem vestram. ${ }^{\text {"79 }}$

Bereits während des 16. Jahrhunderts scheint das Dreiständemodell als Deutungsschema der sozialen Realität nicht mehr genügt zu haben, obwohl es auch in den folgenden Jahrhunderten noch begegnet ${ }^{80}$. Die wachsende Differenzierung der Gesellschaft ließ sich mit dem dreigliedrigen Ordnungsmodell kaum mehr angemessen beschreiben. In einer Fassung der Erzählung von den ungleichen Kindern Evas durch

\footnotetext{
${ }^{13}$ Aus der hessischen Kirchenordnung von 1566, in: Paul Münch (wie Anm. 10) 79.

74 Vgl. ebd.

${ }^{13}$ Erich Trunz (wie Anm. 69) 147.

${ }^{76}$ Karl Martin Bolte, Stefan Hradil, Soziale Ungleichheit in der Bundesrepublik Deutschland (Opladen 1984) 73-89.

7 Paul Münch (wie Anm. 10) 78.

${ }^{78} \mathrm{Vgl}$. die in Anm. 40 genannte Literatur.

${ }^{79}$ Jobannes Winzer (wie Anm. 57) 21.

${ }^{80}$ Hierzu fehlt es generell an Vorarbeiten.
} 
Johann Mathesius aus dem Jahre 1597 ernennt Gott Abel und die anderen braven und wohlerzogenen Kinder Evas als Belohnung für ihr bestandenes Katechismusexamen nacheinander zu König, Graf, Magister, Doktor, Bürgermeister, Pfarrer, Schulmeister und Edelmann; für den bäurisch-ungehobelten Kain und seinen Anhang verbleiben die sozial deklassierten Berufe Vogelsteller, Weidleute, Steiger, Kriegsmann, Botenläufer, Bauer, Drescher, Köhler und Schinder. Die guten Töchter reüssieren zur Kaiserin, Fürstin, Gräfin, die bösen siedelt Gott am unteren Ende der sozialen Hierarchie an: als Holzmagd, Fleischerin, Bäuerin, Käsemutter, Sau- oder Gänsehirtin ${ }^{81}$. Bereits hier ist das dreigliedrige Schema fast völlig aufgegeben. Ubrig bleibt die Zweiteilung der Gesellschaft in kopf- und handarbeitende Schichten, eine Differenzierung, die sich schon früh durchgesetzt zu haben scheint ${ }^{82}$. In den zahlreichen Kleider-, Luxus-, Hochzeitsund Trauerordnungen der Folgezeit ${ }^{83}$ tritt uns eine vielfach geschichtete Gesellschaft entgegen, deren Klassifizierung das alte Modell der ,trois ordres' weitgehend verläßt. Die steuerlich privilegierten oder exemten Gruppen bilden in der Regel die Spitze des ständischen Aufbaus, gefolgt von den steuerlich belastbaren Klassen bis hin zu den besitzlosen und armen Schichten ${ }^{84}$. Das Ständebuch des Hans Sachs, das 1568 mit den Holzschnitten Jost Ammans publiziert wurde, repetiert zwar in den Grundzügen noch die hierarchische Struktur der Gesellschaft mit dem Papst und der Geistlichkeit, dem Kaiser und dem Adel an der Spitze, aber der wachsenden Bedeutung der Künstler, Handwerker und Kaufleute ist schon Rechnung getragen. Sie sind mit über hundert Abbildungen präsent, während dem ersten und zweiten Stand gerade noch vier-

${ }^{81}$ Jobannes Winzer (wie Anm. 57) 41f.

${ }^{82}$ Vgl. Ernst Hinrichs, Einführung in die Geschichte der Frühen Neuzeit (München 1980) 69ff.; Auch die Begriffe Kopf- und Handarbeit begegnen bereits im 16. Jahrhundert und wurden nicht erst, wie Werner Conze vermutet, im 18. Jahrhundert von Zedler geprägt. Vgl. hierzu den Art. ,Arbeit' in: Otto Brunner, Werner Conze, Reinbart Koselleck (Hgg.), Geschichtliche Grundbegriffe (I, Stuttgart 1972) 217. In einer Sirach-Predigt des Johannes Mathesius aus dem Jahre 1589 lesen wir: „Gott hat vns allen aufferlegt die arbeit im Nasenschweiß/ Derhalben sol ein jeglicher/ dieweil es Gott selbst befohlen hat/ arbeiten. Ob aber wol hie der Hand Arbeit gedacht wird/ so begreiffet doch die heilige Schrifft hiemit auch die Kopffarbeit/ Denn wer fleissig studieret/lernet/ lehret/ regieret/ der arbeitet mit dem Kopff/Munde vnd Henden/ vnd wird jhm offt viel sewrer/ denn einem Handwercksmanne oder Bergmann." Vgl. hierzu Paul Münch (wie Anm. 10) 111. Die Neologismen erscheinen als Resultate der Legitimationsnot des Joachimthaler Predigers inmitten seiner schwer handarbeitenden Bergleute.

${ }^{83}$ Liselotte Constanze Eisenbart, Kleiderordnungen der deutschen Stādte zwischen 1350 und 1700. Ein Beitrag zur Kulturgeschichte des deutschen Bürgertums (Bausteine zur Geschichtswissenschaft 32, Göttingen 1962); Veronika Baur, Kleiderordnungen in Bayern vom 14. bis zum 19. Jahrhundert (Miscellanea Bavarica Monacensia 62, München 1975); Alfred Fiedler, Die Reichskleiderordnungen in der Zeit der frühbürgerlichen Revolution als Instrument zur Stabilisierung der feudalen Ständeordnung, in: Hermann Strobach (Hg.), Der arm man 1525. Volkskundliche Studien (Veröffentlichungen zur Volkskunde und Kulturgeschichte 59, Berlin 1975) 89-102; vgl. auch Michael Stolleis, Pecunia Nervus Rerum. Zur Staatsfinanzierung in der Frühen Neuzeit (Frankfurt a. M. 1983).

${ }^{84}$ Vgl. hierzu Diedrich Saalfeld, Die ständische Gliederung der Gesellschaft Deutschlands im Zeitalter des Absolutismus. Ein Quantifizierungsversuch, in: VSWG 67 (1980) $460 \mathrm{f}$. 
zehn bildliche Darstellungen reserviert bleiben ${ }^{85}$. Auch Christoph Weigels,Abbildung der Gemein-Nützlichen Haupt $=$ Stände aus dem Jahre 1698 erinnert in der Vorrede noch an die von Gott eingesetzten drei Hauptstände, den Regier-, Lehr- und Nährstand, aber die 212 Kupfer verlassen diese Disposition und lösen sich gänzlich vom alten Schema. Auf den Regenten des ersten Kupfers folgt der Ingenieur, der Geistliche tritt erst spāt auf und ist zwischen Seiler und Schulmeister gestellt. Das gesamte Werk ist ein Spiegel der gewandelten Situation, ein Zeugnis für die Bedeutung, welche die hochspezialisierten technischen und handwerklichen Berufe inzwischen errungen haben $^{86}$. Eine Welt kündigt sich an, der Produktion und Produktivität zunehmend wichtig wird $^{87}$, eine Welt, in der den handarbeitenden Schichten eine neue gesellschaftliche Rolle zuzuwachsen beginnt.

Daß man sich im 18. Jahrhundert den Bau der Gesellschaft und des Staates zunehmend im Bild einer Maschine oder einer Pyramide vergegenwärtigte ${ }^{88}$, während dem 16. und 17. Jahrhundert eher der ,Körper' oder der ,Ständebaum ' als angemessene Symbole zur Verdeutlichung der Gesellschaftsstruktur erschienen waren ${ }^{89}$, signalisiert den Wandel von einer mehr organisch bestimmten zu einer überwiegend mechanischgeometrischen Gesellschaftsmetaphorik ${ }^{90}$.

Die alten Bilder und Modelle von der rechten Gliederung der Gesellschaft haben sich daneben aber bis zum Ausgang der Frühen Neuzeit behaupten können. Noch im Jahre 1800 leitete der evangelische Pfarrer Rudolph Gottlieb Beyer in einer Predigt über das Sprichwort ,Ordnung erhält die Welt' ganz traditionalistisch die Organisation der Gesellschaft und die Einrichtung des individuellen Lebens von der Ordnung der göttlichen Schöpfung, des Makrokosmos, $\mathrm{ab}^{91}$.

Es bleibt die Frage, was die breite Masse der Bevölkerung von diesem hierarchischen, auf dem Prinzip der Ungleichheit basierenden gesellschaftlichen Ordnungsmodell gewußt hat, genauer: War dieser Begriff der, Ordnung' ein Grundwert? Sicher blie-

${ }^{8 s}$ Eigentliche Beschreibung Aller Stände auff Erden/ Hoher vnd Nidriger/ Geistlicher vnd Weltlicher/ Aller Künsten/ Handwercken vnd Hāndeln [...] Franckfurt am Mayn 1568 (Reprint: Hannover 1984).

${ }_{86}$ Christoff Weigel, Abbildung Der Gemein-Nützlichen Haupt $=$ Stände. Von denen Regenten Und ihren So in Friedens = als Kriegs = Zeiten zugeordneten Bedienten an/ biß auf alle Künstler Und Handwercker [...]. Regenspurg 1698 (Reprint: Die bibliophilen Taschenbücher 9, Dortmund 1977).

87 Weiterführend: Jobannes Burkbardt, Das Verhaltensleitbild ,Produktivität' und seine historisch-anthropologische Voraussetzung, in: Saeculum 25 (1974) 277-289.

${ }^{88} J$ Justus Möser, Der Staat mit einer Pyramide verglichen. Eine erbauliche Betrachtung, in: Ders., Anwalt des Vaterlands. Ausgewählte Werke (Leipzig, Weimar 1978) 208-211.

${ }^{89}$ Günther Weydt, Der Stāndebaum. Zur Geschichte eines Symbols von Petrarca bis Grimmelshausen, in: Wolfgang Brï̈ckner, Peter Blickle, Dieter Brewer (Hgg.), Literatur und Volk im 17. Jahrhundert. Probleme populärer Kultur in Deutschland (Wolfenbütteler Arbeiten zur Barockforschung 13, Teil I, Wiesbaden 1985) 273-280 (mit Abbildungen); vgl. auch den Beitrag von Trudl und Rainer Woblfeil in diesem Band.

${ }^{90} \mathrm{Vgl}$. Ablrich Meyer, Mechanische und organische Metaphorik politischer Philosophie, in: Archiv für Begriffsgeschichte 13 (1969); Henning Eichberg, Geometrie als barocke Verhaltensform, in: Zeitschrift für Historische Forschung 4 (1977); Barbara Stollberg-Rilinger, Der Staat als Maschine. Zur politischen Metaphorik des absoluten Fürstenstaats (Berlin 1986).

${ }_{11}$ Paul Münch (wie Anm. 10) 325-332. 
ben den nicht gebildeten Schichten die diffizilen theologischen Begründungen der Ungleichheit in der Welt unverständlich, aber der Konsens der Pfarrer aller christlichen Konfessionen in dieser Frage ${ }^{92}$ dürfte dafür gesorgt haben, daß über Predigt und Katechese die Ordnungsvorstellungen der herrschenden Schichten nach unten weitergegeben wurden ${ }^{93}$. Wichtiger aber war die reale Erfahrung der Ungleichheit, das Eingebundensein in eine Welt, in der im alltäglichen Leben oben und unten klar unterschieden war, eine Welt, in der jeder in der Regel bereits mit der Geburt seinen Status, den er zeitlebens nicht mehr verließ, zugewiesen bekam. Die patriarchalische Erfahrung, die man als Kind von der Herrschaft des Vaters im Haus machte, setzte sich mit den vorgesetzten Obrigkeiten innerhalb der verschiedenen sozialen und beruflichen Gruppen fort, war in der Figur des ,Landesvaters' präsent und gipfelte vielleicht im Bewußtsein, Gott als himmlischen Vater und Herr über alle Herren über sich zu haben ${ }^{94}$. Das Prinzip der hierarchischen Gesellschaftsordnung scheint ein Grundwert der ständischen Gesellschaft gewesen zu sein, auch wenn man einräumen muß, daß die Vorstellungen, die man damit verbunden hat, in den verschiedenen Schichten der Bevölkerung durchaus unterschiedlich gefüllt gewesen sind. Wer Herrschaft nicht ausübte, sondern als Frau, als Kind, als Dienstbote, als Knecht oder Magd, als Bauer oder Bürger zu ertragen hatte, konnte durchaus eigene Vorstellungen von ,Ordnung' entwikkeln, insbesondere den Gedanken, an der Errichtung von Ordnung mitbestimmend teilhaben zu wollen. „Man muß den Schuh nach dem Fuß machen. Drumb muß man viel Leisten haben. Ordnung muß man nach den Leuten richten/ vnd nicht die Leut nach der Ordnung“, oder: „Ordnung vnd Gesetz sol man mit deren Willen machen/ die damit verbunden werden/ denn sie verstehen den Nutzen und Schaden/ sonst werden sie nicht gehalten" - so lesen wir im ,Florilegium Politicum" des Christophorus Lehmann aus dem Jahr $1637^{95}$. Die sozialen Unruhen und Revolten, die seit dem Bauernkrieg den von oben definierten Begriff der Ordnung aufzubrechen suchten, um andere, den eigenen Interessen eher dienliche Ordnungen aufzurichten ${ }^{96}$, zeigen, wie umstritten ein Grundwert der Ständegesellschaft sein konnte. Ihm eignete eben noch nicht die einklagbare Qualität moderner Grundrechte, sein Inhalt war durchaus nicht allgemeinverbindlich definiert, er mußte im Gegenteil ständig in der Auseinandersetzung der unterschiedlichen Gruppierungen seine konkrete Gestalt gewinnen.

Die Gleichheitspostulate, die Freiheitsforderungen, wie sie uns bei sozialen Kon-

\footnotetext{
${ }^{92}$ Das ließe sich aus den Predigtkompendien und Katechismen des 16.-18. Jahrhunderts breit belegen.

${ }^{93}$ Wieviel unten ankam, ist allerdings noch fast völlig unerforscht. Die Visitationsberichte zeigen, $\mathrm{da} ß$ es vermutlich nicht allzu viel gewesen ist, wenigstens bis zum Ende des 16. Jahrhunderts. Vgl. hierzu Gerald Strauss, Luther's house of learning (1978).

94 Paul Münch, Die ,Obrigkeit im Vaterstand' - Zu Definition und Kritik des ,Landesvaters' während der Frühen Neuzeit, in: Daphnis 11 (1982) 15-40.

95 Paul Münch (wie Anm. 10) 140.

${ }^{96}$ Winfried Schulze, Bäuerlicher Widerstand und feudale Herrschaft in der frühen Neuzeit (Stuttgart 1980); Ders. (Hg.), Europäische Bauernrevolten in der frühen Neuzeit (Frankfurt a. M. 1982); Ders. (Hg.), Aufstände, Revolten, Prozesse (Stuttgart 1983).
} 
flikten, in der gelehrten Utopistik ${ }^{97}$, aber auch in den populären Gegenvorstellungen der ,verkehrten Welt ${ }^{\star}$ und des Schlaraffenlandes entgegentreten ${ }^{98}$, um schließlich im aufklärerischen Diskurs wenigstens die Einlösung bürgerlicher Gleichheit und Freiheit durchzusetzen, zeigen, wie gefährdet die hierarchisch gestufte Ordnung zunehmend war. Aus der einen Ordnung erwuchsen viele Ordnungen. Man erkannte die Historizitāt der vordem als unverānderlich angesehenen Ordnung, man entdeckte auch, wie hinderlich sich das allenthalben geforderte Verbleiben im ererbten Beruf und Stand auf die Dynamik der ökonomischen Entwicklung auswirkte.

Es erscheint nicht ausgeschlossen, neben diesem Grundwert der hierarchischen Ordnung weitere, in der Ständegesellschaft wirksame ,Grundwerte‘ zu finden. Sie können allerdings nur noch in aller Kürze angesprochen werden. Das Feld der kollektiven Mentalitäten dürfte noch viele Entdeckungen bieten. Man muß sich hierfür jedoch auf einen schwierigen Weg begeben. Es gilt, nicht nur die veröffentlichten Wertewelten der Oberschichten zu beschreiben, es ist nötig, diesen Werten auch in der alltäglichen Bewährung, im politischen und sozialen Vollzug, nachzuspüren. Die Erforschung der Wertetheorie und -praxis aller übrigen Schichten müßte sich anschließen. Erst dann ließe sich möglicherweise ein kohärenter und konsistenter Kanon von Grundwerten der ständischen Gesellschaft ausmachen.

Abschließend noch einige Hinweise auf Felder, deren weitere Erforschung erfolgversprechend sein dürfte. Sie hängen eng mit dem beschriebenen Komplex der hierarchischen Ordnung zusammen. Jeder Gruppe innerhalb dieser Ordnung eignete ein bestimmtes Maß an Ehre, ein Bewußtsein von der Wichtigkeit des Standes, in den jeder gestellt war. Jeder hatte Anteil am ,symbolischen Kapital der Ehre ${ }^{99}$, einem Kapital, von dem er glaubte, es sei so wenig wie die verfügbare materielle Gütermenge vermehrbar ${ }^{100}$. Ebre bestimmte nicht nur die Kontakte der Individuen und Gruppen der Eliten, die Verteidigung der Ebre prägte, wie Rainer Walz überzeugend nachgewiesen hat, auch die Kommunikation in der dörflichen Gesellschaft ${ }^{101}$. Die alltäglichen Streitigkeiten, Bezichtigungen, Beschimpfungen, Verrufungen und Tätlichkeiten erklären

${ }_{97}$ Michael Winter, Compendium Utopiarum (Stuttgart 1978).

98 Zur gesamteuropäisch verbreiteten Vorstellung der, verkehrten Welt' vgl. Peter Burke (wie Anm. 19) 199-205; zur Utopie vom Schlaraffenland vgl. Martin Müller, Das Schlaraffenland. Der Traum von Faulheit und Müßiggang (Wien 1984); Dieter Richter, Schlaraffenland. Geschichte einer populären Phantasie (Köln 1984); Werner Wunderlich, Das Schlaraffenland in der deutschen Sprache und Literatur, in: Fabula 27 (1986) 54-75; vgl. auch Joachim Scbultz, Gerhard Köpf (Hgg.), Das Insel-Buch der Faulheit (Frankfurt a. M. 1983).

99 Der Begriff stammt von Andreas Grießinger (wie Anm. 17).

${ }^{100} \mathrm{Vgl}$. G. M. Foster, Peasant Society and the image of limited good, in: American Anthropologist 67 (1965) 293-315.

${ }^{101}$ Der Hexenwahn vor dem Hintergrund dörflicher Kommunikation, in: Zeitschrift für Volkskunde 82 (1986) 1-18; vgl. auch Karl-Sigismund Kramer, Die Nachbarschaft als bäuerliche Gemeinschaft (München-Pasing 1954); Bernbard Müller-Wirtbmann, Raufhāndel. Gewalt und Ehre im Dorf, in: Richard van Dülmen (Hg.), Kultur der einfachen Leute (wie Anm. 24) 79-111; zur Geltung von Ehrbegriffen in den unterständischen und außerstāndischen Gruppierungen vgl. die in den Anm. 21 und 22 zitierte Literatur. 
sich aus dem Bestreben, die eigene Ebre auf dem Weg der retorsiven Selbsthilfe zu schützen und zu verteidigen ${ }^{102}$.

Während das aus der hierarchischen Gesellschaftsstruktur erwachsende Prinzip der Ehre eine gesamtgesellschaftlich verbindliche Bedeutung gehabt haben dürfte, können die im Haus, jenem ,von bestimmten Wirtschaftsformen oder einer spezifischen Standesherrschaft“ unabhängigen frühneuzeitlichen „Modell von Herrschaft über-

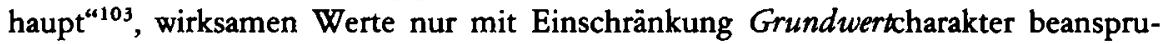
chen. Ihre Geltung war auf die grund- und hausbesitzenden Schichten beschränkt. Für diese Gruppen allerdings erscheinen die im Haus propagierten virtutes oeconomicae als intentional verbindlich ${ }^{104}$, obwohl man über die Bewährung dieser Werte im Alltag auch noch wenig weiß ${ }^{105}$. Die ausstrahlende Kraft der häuslichen Wertewelt auf die gesamte Gesellschaft, ihre Übernahme durch die bürgerliche Bewegung des 18. Jahrhunderts, die sie als Basis der kommenden bürgerlichen Gesellschaft reklamierte - diese zunehmend alle Bevölkerungsschichten umschließende Qualitāt der virtutes oeconomicae sichert den Haustugenden dennoch eine zentrale, wenn auch die Gesamtgesellschaft erst partiell erfassende Rolle im Kanon der frühneuzeitlichen Grundwerte ${ }^{106}$.

Erst eine genauere, betont quellenorientierte Analyse der Spannungsfelder der ständisch fragmentierten frühneuzeitlichen Gesellschaft, die sich mit dem Absolutismus zur einen Gesellschaft zu formieren beginnt, dürfte eine umfassende Gesamtschau des frühneuzeitlichen Werte- und Normenkanons ermöglichen. Insofern bilden die drei Potenzen Staat, Religion und Kultur, denen man heute Wirtschaft und Gesellschaft als zunehmend autonome Größen beigesellen möchte, nach wie vor die (alt)bewährten Forschungsfelder. In ihren stets neu zu bestimmenden wechselseitigen „Bedingtheiten“ liegt der Schlüssel für ein tieferes Verständnis des frühneuzeitlichen Wertewandels.

${ }^{102}$ Zur Begriffsgeschichte vgl. auch Friedrich Zunkel, Art. ,Ehre, Reputation', in: Otto Brunner, Werner Conze, Reinbart Koselleck (Hgg.), Geschichtliche Grundbegriffe (Bd. 2, Stuttgart 1975) 1-63. Hier ist allerdings die angeschnittene Problematik nicht thematisiert.

${ }^{103}$ Josef Engel (wie Anm. 39) 400.

${ }_{104}$ Vgl. hierzu generell Paul Münch (wie Anm. 10) 22-26.

${ }^{103} \mathrm{Vgl}$. jedoch die Studie von Renate Blickle in diesem Band.

${ }^{106}$ Vgl. hierzu generell Paul Münch (wie Anm. 10). 